\title{
Fenomena Tarekat di Zaman Now: Telaah atas Ajaran dan Amalan TQN Suryalaya
}

\author{
Asep Usman Ismail \\ UIN Syarif Hidayatullah Jakarta \\ asep.usman@uinjkt.ac.id
}

\begin{abstract}
Abstraks: Tarekat merupakan anak kandung tasawuf amali. Secara harfiah tarekat berasal dari kata al-tharîqah yang berarti cara, jalan atau metodologi. Dalam tasawuf tarekat adalah cara, jalan atau metodologi guna mencapai tujuan tasawuf, yaitu kesucian jiwa, kedekatan diri dengan Allah dan merasakan kehadiran-Nya. Tasawuf amali dibangun di atas prinsip "ilmu amaliah, amal ilmiah" yang biasanya dipraktekkan dengan mengikuti tarekat di bawah bimbingan seorang mursyid. Pembahasan tentang tarekat bisa dilihat dari lima aspek yang berikut: Pertama, tarekat ditinjau dari segi etimologi. Kedua, tarekat sebagai peringkat penghayatan keislaman kaum Muslimin. Ketiga, tarekat sebagai jalan, cara metode yang dilakukan para sufi dalam menyucikan jiwa, mendekatkan diri kepada Allah dan merasakan kehadiran-Nya di dalam kalbu. Keempat, tarekat sebagai metode psikologis yang dilakukan mursyid dalam membimbing murid-muridnya guna merasakan dzikir kalbu. Kelima, tarekat sebagai organisasi para pengamal tasawuf di bawah kepemimpinan seorang mursyid.
\end{abstract}

Kata Kunci: Tarekat, Amalan

Permalink/DOI: http://doi.org/10.15408/dakwahv22i1.12068

\section{Pendahuluan}

\section{Pengertian dan Perkembangan}

Tarekat merupakan anak kandung tasawuf amali. Secara harfiah tarekat berasal dari kata altharîqah yang berarti cara, jalan atau metodologi. Dalam tasawuf tarekat adalah cara, jalan atau metodologi guna mencapai tujuan tasawuf, yaitu kesucian jiwa, kedekatan diri dengan Allah dan merasakan kehadiran-Nya. Tasawuf amali dibangun di atas prinsip "ilmu amaliah, amal ilmiah" yang biasanya dipraktekkan dengan mengikuti tarekat di bawah bimbingan seorang mursyid. Pembahasan tentang tarekat bisa dilihat dari lima aspek yang berikut: Pertama, tarekat ditinjau dari segi etimologi. Kedua, tarekat sebagai peringkat penghayatan keislaman kaum Muslimin. Ketiga, tarekat sebagai jalan, cara metode yang dilakukan para sufi dalam menyucikan jiwa, mendekatkan diri kepada Allah dan merasakan kehadiran-Nya di dalam kalbu. Keempat, tarekat sebagai metode psikologis yang dilakukan mursyid dalam membimbing murid-muridnya guna merasakan dzikir kalbu. Kelima, tarekat sebagai organisasi para pengamal tasawuf di bawah kepemimpinan seorang mursyid.

Pertama, secara etimoligi. Menurut Ibn Manzhur, tarekat secara etimologi berasal dari bahasa Arab yang dapat diringkaskan sebagai berikut: (1) berasal dari kata al-tharq (th-r-q) yang berarti garis di bumi atau garis pada suatu apa pun. (2) berasal dari kata al-tharîqah yang berarti al-sîrah, perjalanan hidup atau biografi; (3) berasal dari al-tharîqah yang berarti al-madzhab, 
pemikiran atau aliran; (4) berasal dari al-tharîqah yang berarti al-hâlah, keadaan; dan (5) berasal dari al-tharîqah yang berarti al-'umud, tiang. ${ }^{1}$ Menurut Kamus al-Munjid, tarekat berasal dari altharîqah yang berarti al-sabîl, jalan.² Sementara itu, menurut Muhammad 'Aqil bin 'Ali alMahdali, tarekat berasal dari al-tharîqah yang berarti jalan yang ditetapkan atau jalan yang biasa dilewati manusia; ${ }^{3}$ sedangkan dalam A Dictionary of Modern Written Arabic disebutkan bahwa tharîqah berarti jalan, cara, metode, system, prosedur, keyakinan atau agama. 4

Sejalan dengan penjelasan kebahasaan tersebut, Nurcholish Madjid menyimpulkan bahwa al-tharîqah memiliki makna yang sama dengan syari’ah, shirât, dan minhâj yang berarti jalan, cara, metode atau sistem. Keempat kata tersebut mengisyaratkan bahwa peruntukkan bagi manusia atas dasar kasih sayang Allah kepada hamba-Nya.5 Ajaran Islam pada hakikatnya bukan tujuan, tetapi jalan menuju Allah yang berasal dari Allah dan diperuntukkan bagi manusia.

Kedua, tarekat sebagai peringkat penghayatan keislaman kaum Muslimin. Istilah al-tharîqah dalam tasawuf sering dihubungkan dengan tiga istilah lain, yakni, al-syarî'ah (syariat) al-ma'rifah (ma'rifat) dan al-haqîqah (hakikat). Keempat istilah tersebut sering digunakan untuk menggambarkan peringkat penghayatan keagamaan kaum Muslimin. ${ }^{6}$ Penghayatan keagamaan peringkat awal disebut syari'at, peringkat kedua disebut tarekat, peringkat ketiga disebut ma'rifat dan peringkat keempat dinamakan hakikat. Berdasarkan peringkat penghayatan keagamaan ini, tidak mengherankan jika di tengah-tengah masyarakat ditemukan adanya pengamal tarekat yang memandang diri mereka dan kelompoknya merupakan kelompok khusus di antara umat Islam, karena keyakinan bahwa peringkat pengamalan keislaman mereka lebih tinggi dibandingkan dengan rata-rata orang Islam pada umumnya yang hanya mengamalkan Islam pada peringkat syari'at. Mereka memandang bahwa syari'at ibarat kerangka, sedangkan tasawuf merupakan ruhnya. Mengamalkan Islam yang hanya berorientasi syari'ah seperti jasad tanpa ruh. Dalam persepsi mereka, syari'ah itu rendah dan kaum Muslimin yang hanya mengamalkan syari'ah itu seperti murid sekolah yang tidak naik kelas; sedangkan para pengamal tarekat merupakan muridmurid pilihan yang naik kelas sehingga merasa bahwa peringkat keberagaman mereka lebih tinggi dibandingkan dengan kaum Muslimin yang bukan pengamal tarekat.

Ketiga, tarekat merupakan metodologi yang dilakukan seorang sufi dalam mencapai tiga tujuan tasawuf, yaitu tazkiyat al-nafs, menyucikan jiwa dari berbagai penyakit hati; taqarrub ila Allah, mendekatkan diri kepada Alah dengan sedekat-dekatnya; dan hudhûr al-qalb ma'allâh, merasakan kehadiran Allah di dalam kalbu. Oleh sebab itu, tarekat secara lengkap berati tharîqat al-shûfiyyah, cara, jalan atau metodologi para sufi dalam menyucikan jiwa, mendekatkan diri kepada Allah dan merasakan kehadiran-Nya di dalam kalbu.

Dalam perkembangan selanjutnya, terjadi pergeseran dari wacana tharîqat al-shûfiyyah secara umum kepada tokoh sufi tertentu yang membakukan amalan sebuah tarekat sehingga dikenal Tharîqat Qadîriyyah berarti cara, jalan atau metodologi yang dirintis Syaikh Abdul Qadir al-Jaylani. Demikian juga Tharîqat Naqsyabandiyyah adalah cara, jalan atau metodologi yang dirintis oleh Syaikh Naqsyabandi. 
Keempat, tarekat dalam pengertian metode psikologis yang dilakukan seorang mursyid dalam membimbing murid-muridnya guna merasakan dzikir kalbu. Mula-mula tarekat hanya berarti jalan menuju Tuhan yang ditempuh seorang sufi secara individual; akan tetapi para sufi itu kemudian mengajarkan tharîqah kepada murid-murid, baik secara individu maupun secara kelompok.7 Dari sini terbentuklah tarekat, dalam pengertian metode penyucian jiwa dan pendekatan diri kepada Allah di bawah bimbingan seorang mursyid. Sejak itu muncul beberapa tarekat yang dinisbahkan kepada sufi yang merintisnya seperti, Tarekat Qadiriyah, Tarekat Naqsyabandiyah, Tarekat Qadiriyah wa Naqsyabandiyah, Tarekat Syathariyah, Tarekat Samaniyah, Tarekat Khalwatiyah, Tarekat Tijaniyah, Tarekat Idrisiyah, Tarekat Rifa'iyah dan lain-lain. Oleh sebab itu, tarekat bermacam-macam sesuai dengan jumlah sufi yang memperkenalkan metode mereka masing-masing.

Ajaran dan amalan tarekat dilihat dari kesesuaiannya dengan arkân al-dîn (rukun agama), yaitu akidah, syari'ah dan akhlak terbagi ke dalam dua bagian. Ada tarekat yang sah dan ada pula tarekat yang tidak sah. Tarekat yang sah disebut tarekat mu'tabarah, sedangkan tarekat yang tidak sesuai dengan arkân al-dîn, disebut tarekat ghair mu'tabarah. ${ }^{8}$

Di Indonesia terdapat beberapa tarekat mu'tabarah yang masuk dan berkembang bersamaan dengan masuk dan berkembangnya Islam di Nusantara. Islam menjadi agama mayoritas di negeri ini tidak terjadi tiba-tiba, tetapi merupakan hasil perjuangan para mujahid dakwah yang merintis gerakan Islamisasi di Nusantara. Mereka adalah para sufi yang di Jawa dikenal dengan sebutan walisanga. ${ }^{9}$

Kelima, tarekat sebagai organisasi para pengamal tasawuf amali di bawah kepemimpinan mursyid membentuk sub kultur yang berbeda dari kultur masyarakat pada umumnya. Dalam organisasi tarekat, mursyid berada pada puncak piramida. Ia menempati posisi sentral dalam mengarahkan amaliah para pengikut tarekat, bahkan mengontrol totalitas kehidupan mereka. Mursyid tarekat pada umumnya memiliki gaya kepemimpinan kharismatik dengan komunikasi yang bersifat one way communication, komunikasi satu arah. Pada umumnya content atau isi komunikasi mursyid terhadap murid bersifat nasihat, perintah atau maklumat yang tak seorang pun di antara murid-murid tarekat berani mempertanyakan apa lagi menolaknya.

\section{Pembahasan}

\section{Delapan Komponen Pokok Tarekat}

Tarekat sebagai metode psikologis yang dilakukan mursyid dalam membimbing muridmurid tumbuh menjadi sebuah metodologi sistemik yang memiliki delapan komponen pokok, yaitu: Mursyid, murid, wirid, talqin, bay'at, silsilah, tempat dan adab. ${ }^{10}$

Pertama, mursyid. Secara bahasa mursyid berarti pembimbing atau guru, tepatnya guru tarekat. Mursyid adalah pemimpin tertinggi sebuah tarekat. Setiap tarekat memiliki mursyid yang membimbing murid-murid dalam melakukan berbagai amaliah tarekat seperti shalat, wirid, dzikir dan doa. Mursyid tarekat memiliki otoritas mutlak dalam menentukan ajaran dan amalan tarekat. 
Keberadaan guru tarekat yang disebut syaikh atau mursyid sangat penting bahkan mutlak. Keberadaan syaikh tarekat di hadapan para murid tarekat seperti kedudukan Nabi Muhammad saw di hadapan para sahabat dalam mengajarkan hakikat dan syari'ah kepada mereka, karena, menurut keyakinan para pengamal tarekat, Nabi Muhammad saw diutus dengan membawa syari'ah dan hakikat.11 Syaikh tarekat mewarisi aspek hakikat dari Nabi Muhammad saw, sedangkan para ulama fiqh mewarisi aspek syari'ah. Dua-duanya adalah wakil Nabi saw dalam mengembangkan Islam dari masa ke masa. Syaikh tarekat adalah wakil Nabi Muhammad saw dalam bidang hakikat. ${ }^{12}$

Kedua, murid. Secara etimologi murîd berarti seorang yang berkehendak, berharap atau menginginkan sesuatu. Dalam tarekat, murid adalah para penempuh jalan ruhani yang berharap mendapat keridhoan Allah, mengenal dan mencintai-Nya. Murid adalah orang-orang yang menghendaki perjumpaan dengan Allah melalui ibadah, riyadhah, mujahadah dan munajat di bawah bimbingan mursyid. Ketaatan total murid kepada mursyid kunci keberhasilan murid dalam mencapai tujuan tarekat.

Ketiga, wirid. Secara etimologi wirid berarti sesuatu yang terjadi berulang-ulanag. Dalam tarekat wirid adalah dzikir yang dilakukan secara rutin. Wirid TQN intinya adalah dzikir setiap selesai shalat lima waktu dengan mengucapkan kalimat الإله إلا الله 165 kali; tawajjuh dengan dzikir kalbu atau dzikir khafi, dan mengikuti khataman, pembacaan wirid secara berjamaah yang dipimpin seorang pemandu.

Keempat, talqîn yang secara etimologi berarti nasihat. Dalam TQN talqin adalah proses penyadaran atau bimbingan ruhani. Talqin merupakan proses bimbingan dzikir dalam TQN untuk mendidik calon murid agar perasaannya tersambung dengan Allah. Talqin merupakan pintu gerbang masuk TQN, mengikuti proses pendidikan dan pelatihan ruhani yang berbasis dzikir lisan dan dzikir kalbu. Metode ini merupakan bimbingan psiko-spiritual yang dirintis oleh Syaikh Abdul Qadir al-Jaylani dan Syaikh Bahauddin al-Naqsyabandi. Essensi talqin adalah metodologi psikologis yang dilakukan mursyid dalam membimbing calon murid agar mengaktifkan rasa dan menghubugkannya dengan Allah. Dengan mengikuti talqin, calon murid resmi menjadi ikhwan, suadara sesama pengamal TQN.

Kelima, bay'at yang secara etimologi bay'at berarti janji atau perjanjian di antara dua orang atau dua pihak. Dalam tarekat, bay'at adalah perjanjian antara murid dengan mursyid. Murid berjanji akan mengamalkan dzikir yang diajarkan guru dengan sebaik-baiknya. Janji itu hakikatnya kepada Allah bukan kepada mursyid. Seorang calon pengamal tarekat diharuskan berjanji setia kepada mursyid, bahwa ia akan menaatinya, memegang teguh ajaran dan mengamalkan wirid yang diajarkan guru kepadanya; tidak mempertanyakan atau meragukan ajaran dan amalan guru.

Keenam, silsilah yang secara etimologi berarti mata rantai. Dalam tarekat, silsilah adalah mata rantai yang menghubungkan kesinambungan ruhani di antara mursyid dengan mursyid sebelumnya hingga sampai kepada mursyid tertinggi, Rasulullah saw. "Konsep silsilah 
mengokohkan otoritas guru. Melalui silsilah jalur transmisi otoritas dan barakah dibangun. Dengan cara ini, kekuatan spiritualitas syaikh tarekat dapat ditransmisikan kepada para murid, terutama kepada mursyid berikutnya”. ${ }^{13}$

Ketujuh, tempat diklat ruhani para sufi yang disebut dengan beberapa nama. Ada yang menyebutnya zawiyah, yang berarti pojok. Istilah zawiyah pada awalnya berarti salah satu sudut masjid yang disediakan bagi para sufi pengembara yang membutuhkan tempat istirahat. Setiap mursyid tarekat mempunyai zawiyah, tempat murid-muridnya berkumpul mengadakan latihan spiritual. Ada juga yang menyebutnya ribâth, yang berarti tempat mengikat. Para sufi yang menempati ribâth seakan-akan sedang mengikat jiwanya agar tidak liar. Istilah ribâth ada hubungannya dengan râbitah, ikatan batin murid dengan mursyid. Selain itu, dikenal pula istilah funduq, yang berarti pondok, tempat mereka berkumpul. Istilah funduq menjadi cikal bakal pondok pesantren. Dalam TQN tempat diklat ruhani itu disebut madrasah.

Kedelapan, adab yang berarti etika yang mengatur hubungan murid dengan mursyid dalam tarekat. Adab merupakan kunci keberhasilan murid tarekat. Menurut Ibn 'Arabi, "seorang murid di hadapan gurunya hendaklah bersikap seperti mayat di hadapan orang yang memandikannya. Murid tidak boleh berprasangka buruk atau ragu terhadap gurunya. Tidak boleh duduk pada tempat yang biasa diduduki gurunya. Tidak boleh memakai barang yang biasa dipakai gurunya. Apabila mursyid menyuruhnya mengerjakan sesuatu, hendaklah segera mengerjakannya. Murid tidak boleh mengajukan usul apa pun kepada mursyid. Jika murid melihat gurunya berjalan ke suatu arah, tidak boleh bertanya ke mana gurunya pergi. Seorang murid tidak boleh menikahi janda gurunya, ketika gurunya telah bercerai atau wafat”. ${ }^{14}$ Murid yang berani melawan gurunya dalam tarekat, menurut Syaikh Yusuf al-Maqassari seperti dikutip Tudjimah, dipandang telah melawan Allah SWT, karena mursyid tarekat itu bersama Allah SWT dan ia berdiri pada mazhhariyah Allah, penampakan-Nya, menyatu dengan Nur Muhammad. Oleh sebab itu, penyerahan diri seorang murid kepada syaikh tarekat dalam semua hal hukumnya wajib. ${ }^{15}$

Penghormatan dan ketaatan murid kepada mursyid merupakan komponen penting dalam menentukan keberhasilan pembelajaran rohani. Menurut Ibn Umar Khan, "murid yang tidak hormat dan tidak taat kepada guru, maka hancurlah adabnya kepada Nabi Muhammad SAW, karena mursyid itu adalah wakil Nabi Muhammad SAW dalam kepemimpinan rohani sampai di hadirat Allah". ${ }^{16}$

Berdasarkan keterangan ini, "murid-murid tarekat harus memelihara adab kepada mursyid yang membimbing ruhani mereka. Mereka tidak boleh berdiskusi, menyanggah atau mempertanyakan pesan-pesan gurunya". ${ }^{17}$ Adab kepada mursyid dimaksudkan agar murid memperoleh limpahan berkah dari mursyid guna meningkatkan maqamat-nya. Limpahan berkah itu atas izin Allah SWT, hanya diberikan kepada murid yang mengabdi kepada gurunya dengan tulus, bukan murid yang ragu, suka bertanya atau mempertanyakan ajaran dan amalan mursyid, meskipun menurut penglihatan murid bahwa mursyid mereka telah menyimpang dari ajaran 
Allah dan Rasul-Nya; sebab mursyid dapat memberikan syafaat kepada murid-muridnya yang percaya kepadanya di akhirat nanti. ${ }^{18}$

\section{Tarekat Qadiriyah wa Naqsyabandi-yah (TQN)}

TQN merupakan salah satu tarekat mu'tabarah di Indonesia. Tarekat ini gabungan dari lima tarekat, yaitu Qadiriyah, Naqsyabandiyah, Anfasiyah, Junaydiyah dan Muwâfaqah yang difusikan oleh Syaikh Ahmad Khatib ibn Abd al-Ghaffar al-Sambasi al-Jawi (w. 1875 M.), seorang guru besar di Masjid al-Haram yang berasal dari Kampung Dagang, Sambas Kalimantan Barat ${ }^{19}$ sehingga beliau dianggap sebagai pendiri TQN. Kelima tarekat ini masing-masing memiliki keunikan dalam amaliah dzikirnya. Tarekat Qadiriyah dengan dzikir jahar (suara keras), Naqsyabandiyah dengan dzikir khafi (diam tanpa kata dan suara), Anfasiyah dengan dzikir pernafasan, Junaydiyah dengan dzikir setiap hari dalam seminggu dengan kalimat-kalimat dzikir tertentu dan Muwâfaqah dengan dzikir al-Asmâ` al-Husnâ. ${ }^{20}$

Untuk menghindari kultus terhadap dirinya, Syaikh Ahmad Khatib tidak menisbahkan tarekat hasil penggabungan ini kepada dirinya, tetapi kepada dua dari lima pendiri tarekat yang digabungkan itu. Beliau memperhatikan peringatan Syaikh 'Abd al-Qadir melalui wasiatnya.21 Beliau menegaskan: "Seandainya gagasan yang terlintas dalam benak kamu tidak sesuai dengan sunnah Rasul dan ayat-ayat Al-Qur`an, bahkan bertentangan, hendaklah engkau membuang jauhjauh gagasan itu. Hindarilah jalan pikiran atau gagasan tersebut karena sesungguhnya hanya menyesatkan diri kamu saja. Percayalah, gagasan yang terlintas di dalam benak kamu, jika bertentangan dengan Al-Qur`an dan Sunnah Rasulullah saw., maka gagasan itu datangnya dari syetan”. ${ }^{22}$ Meskipun demikian, menurut penelitian Pabali Musa, ada beberapa hal yang perlu dikritisi terhadap Syaikh Ahmad Khatib dalam menggabungkan dan menamakan tarekatnya. Pertama, ia hanya mengemukakan satu silsilah tarekat saja yaitu silsilah Tarekat Qâdiriyah, padahal ajarannya merangkum ajaran lima tarekat. Kedua, ia juga tidak terbuka memperkenalkan tiga tarekat lain yang diambilnya selain Qâdiriyah dan Naqsyabandiyah, yaitu Tarekat Anfasiyah, Tarekat Junaydiyah dan Tarekat Muwâfaqah ${ }^{23}$ sehingga yang digabungkan seakan-akan hanya dua tarekat saja, yaitu Tarekat Qâdiriyah dan Tarekat Naqsyabandiyah.

Dari lima tarekat tersebut, Tarekat Qâdiriyah merupakan tarekat yang paling besar karena ketokohan pendirinya. Syaikh Abd al-Qâdir al-Jaylani yang dikenal dengan beberapa gelar kehormatan sebagai berikut: Muhyî al-Dîn wa al-Sunnah, tokoh yang menghidupkan agama dan sunnah Nabi saw; Mumît al-Bid'ah, tokoh yang mematikan bid'ah; Imâm al-Zâhid, pemimpin yang askestis terhadap kemewahan dunia; dan Al-Arif al-Qudwah, tokoh yang mengenal Allah dan pemimpin teladan. ${ }^{24}$ Beliau mengajak murid-muridnya bekerja keras untuk kehidupan, karena mengamalkan tarekat tidak berarti membelakangi kehidupan”. 25 "Beliau juga, menurut Syaikh Abd al-Wahhâb al-Sya'rânî, mengingatkan para pengikut tarekat agar tetap berpegang teguh kepada Sunnah Rasulullah saw dan syari'at Islam; dan mengingatkan bahwa setan banyak menyesatkan 
ahli tarekat dengan cara menggodanya agar meninggalkan syari'at, karena merasa sudah mengamalkan tarekat”. ${ }^{26}$

\section{TQN Pondok Pesantren Suryalaya}

TQN Suryalaya, menurut Zamakhsyari Dhofier, merupakan tarekat terbesar di Pulau Jawa. ${ }^{27}$ Salah satu pusat penyebarannya di Pesantren Suryalaya, Tasikmalaya Jawa Barat. Pesantren ini diririkan oleh Syaikh Abdullah Mubarok bin Nur Muhammad terkenal Abah Sepuh, pada 5 September 1905 di Kampung Godebag, Desa Tanjungkerta, Kecamatan Pageur Ageung, Tasikmlaya yang juga mursyid TQN ke-36. ${ }^{28}$ Kepemimpinan TQN kemudian digantikan oleh K.H. Ahmad Shohibul Wafa Tadjul Arifin, terkenal Abah Anom sejak 13 Februari 1956. ${ }^{29}$

Essensi amalan atau amaliah utama TQN pada dasarnya hanya satu, yaitu dzikrullâh, dzikir kepada Allah. Sebab, menurut Abah Anom, di dalam dzikir itu ada perjuangan untuk membuka kalbu, mencari ridha Allah dan memenuhi kebutuhan rohani seorang Muslim. Berbagai wirid apa pun hanya akan bermanfaat untuk membuka kalbu yang tertutup jika wirid itu dipadukan dengan kalbu yang dipenuhi kesadaran tentang dzikir kepada Allah (dzikir khafi). ${ }^{30}$ Amalan atau amaliah TQN bisa dibagi menjadi tiga bagian, yaitu amaliah harian, mingguan dan bulanan. Amaliah harian adalah wirid dzikir, amaliah mingguan adalah wirid khataman dan amaliah bulanan adalah mengikuti pengajian manakiban. Singkatnya amaliah TQN adalah dzikir, khataman dan manakiban. ${ }^{31}$

Istilah manakiban berasal dari kosa kata bahasa Arab manqabah dalam bentuk tunggal atau manâqib dalam bentuk jamak yang secara denotative berarti tinggi, luhur atau jalan yang terbentang di puncak gunung; sedangkan secara konotatif manqabah atau manâqib berarti perbuatan mulia atau tindakan terpuji yang bernilai tinggi atau luhur. Sementara itu, secara popular manâqib berarti riwayat hidup atau biografi. Dalam makalah ini yang dimaksud dengan manâqib adalah riwayat hidup atau biografi Syaikh 'Abd al-Qâdir al-Jaylânî, sedangkan yang dimaksud dengan manakiban adalah pengajian bulanan di lingkungan para ikhwan TQN Suryalaya yang salah satu acara intinya adalah membacakan manqabah, penggalan kisah kehidupan Syaikh 'Abd al-Qâdir al-Jaylânî.3²

Sejak Abah Anom wafat pada tahun 2011, murid- murid TQN terbelah dua. Pertama, mereka yang meyakini bahwa Abah Anom tetap merupakan mursyid TQN. Tidak ada mursyid baru yang menggantikan beliau, karena hingga akhir hayat, beliau tidak pernah menunjuk penggantinya dan tidak meninggalkan pesan apa pun tentang suksesi kepemimpinan TQN. Pandangan ini merupakan pandangan mayoritas para Wakil Talqin TQN dan para ikhwan pada umumnya sebagaimana disebutkan oleh K.H. Beben, salah seorang Wakil Talqin TQN asal Pamijahan, Tasikmalaya: "Kalau seseorang berani menyatakan dirinya mursyid, apalagi kepada orang banyak, maka ada kekhawatiran bahwa dirinya mengaku lebih baik dari yang lain. Ini yang seharusnya ditakuti. Itulah sebabnya Pangeresa Abah Anom tidak menyebutkan dan tidak menunjuk seseorang menjadi mursyid. Syaikh Shahibul Wafa Tadjul Arifin tidak mencetuskan 
mursyid pengganti beliau, itu karena menjaga keikhlasan atau kesucian hati seorang mursyid, supaya tidak terkontiminasi oleh pengakuan menjadi mursyid”.33 Pak Beben mengaku, "menjalankan amanah mursyid itu yang kami lakukan sekarang. Khataman dan manaqiban kami lakukan bersama-sama seperti biasa adanya. Amanah mursyid itu sudah menjadi isyarat bagi kami untuk memberikan talqin bagi orang yang mau belajar dzikir. Menerima amanah mursyid itu tidak berarti pengakuan menjadi mursyid. Ini isyarat untuk menjalankan amanah seperti air mengalir saja”. 34

Kedua, murid- murid yang mendukung deklarasi sepihak Ajengan Gaos, salah seorang Wakil Mursyid (Wakil Talqin), yang menyatakan dirinya sebagai Mursyid TQN ke- 38, menggantikan Abah Anom. Deklarasi Pak Gaos ditolak oleh seluruh Wakil Talqin Abah Anom dan mayoritas ikhwan TQN yang merupakan murid-murid setia Abah Anom, bahkan beliau dipecat dari jabatannya sebagai Wakil Talqin, namun menurut Pak Beben bukan dipecat, tetapi keluar sendiri. Lebih jauh Wakil Talqin asal Pamijahan ini menyatakan: "Dalam rapat-rapat para Wakil Talqin TQN Pondok Pesantren Suryalaya yang rutin diselenggarakan 6 bulan sekali yang bersangkutan tidak pernah hadir. Kita (para wakil talqin) ingin menjaga kekompakan dalam khidmat kepada Pangerasa Mursyid Syaikh Ahmad Shohibul Wafa Tadjul Arifin. Kita tidak pernah mengeluarkan seorang pun di antara para wakil talqin, tetapi yang bersangkutan terus menerus tidak menghadiri undangan pertemuan, maka yang bersangkutan bukan dikeluarkan, tetapi keluar sendiri dari kedudukannya sebagai wakil talqin TQN".35

Abah Gaos tidak bergeming. Ia terus menyatakan dirinya sebagai mursyid TQN ke-38 dengan misi "mengamankan, melestarikan dan mengembangkan ajaran Abah Anom”. Dalam Majalah Nuqthoh No 7 Tahun XI Rajab 1435 H/Mei 2014 di bawah judul "Abah Aos Q.S. (qaddasallahu sirrah) Sang Pelestari Cahaya" dinyatakan secara terbuka tentang kemursyidan Abah Gaos. "Syaikh Muhammad Abdul Gaos Saefulloh Maslul Al-Qodiri An-Naqsyabandi Al-Kamil Wali Mursyid TQN Suryalaya Silsilah ke-38". ${ }^{36}$ Pernyataan ini bukan hanya menegaskan bahawa Ajengan Gaos sudah dinobatkan sebagai Mursyid TQN ke-38 menggantikan Abah Anom, tetapi juga menyatakan bahwa Ajengan Gaos adalah seorang waliyullah, wali Allah, al-Kamil, yang sempurna. Abah Gaos pun diyakini sebagai seorang yang memiliki keistimewaan atau karamah. "Berbagai keistimewaan gerak dakwah Abah Aos dalam mengembangkan TQN Suryalaya pada zaman kemursyidan Abah Anom tidak dimiliki oleh Wakil Talqin lainnya. Sedemikan sehingga pantaslah jika pada saat ini, Abah Aos Qs menjadi penerus Abah Anom dalam melestarikan cahaya TQN Suryalaya. Keistimewaan Abah Aos Qs dalam melestarikan cahaya TQN Suryalaya tentu saja jika harus ditulis keseluruhan daripada keistimewaan tersebut, maka satu buku pun tidak akan cukup untuk memuatnya. Jangankan satu buku, jika pun seluruh ikhwan TQN Suryalaya bimbingan Abah Aos Qs diberikan tugas untuk menuliskan keistimewaan-keistimewaan beliau versi masing-masing, maka tentu saja tidak akan mencukupi untuk dimuat di salah satu perpustakaan, sekalipun itu satu perpustakaan terbesar di dunia”. ${ }^{37}$ 
Ajaran dan amalan TQN Suryalaya bisa ditelusuri pada beberapa publikasi, baik berupa buku, kitab maupun maklumat yang diterbitkan oleh atau atas nama Pesantren Suryalaya, di antaranya:

1. Kitab Miftah al-Shudur, kitab ini disusun oleh Abah Anom yang merupakan panduan bagi para ikhwan TQN dalam mengamalkan ajaran dasar dan amalan utama TQN;

2. "Kitab 'Uqudul Juman: Thoriqoh Qodiriyayh Naqsyabandiyyah Pondok Pesantren Suryalaya”. ${ }^{8}$ Buku ini merupakan panduan amalan TQN yang disusun pada masa Abah Anom, kemudian dicetak ulang pada masa Abah Gaos.

3. "Amaliah Mursyid: Amalan TQN Pondok Pesantren Suryalaya"39 Bukun ini merupakan panduan amalan TQN yang disusun ulang pada masa Abah Gaos.

4. Buku berjudul "Saefulloh Maslul Menjawab 165 Masalah"40 yang disusun Abah Gaos. Buku ini disusun dalam bentuk tanya jawab, dalam gaya bahasa lisan yang membahas pelik-pelik TQN, Buku ini merupakan buku pintar bagi para mubaligh TQN dan para ikhwan pada umumnya.

5. Buku berjudul "Abah Anom Wali Fenomenal Abad 21 dan Ajarannya". Buku ini dimaksudkan oleh penulisnya ${ }^{41}$ sebagai buku biografi yang berisi pujian terhadap ketokohan Abah Anom yang meyakini bahwa Abah Anom adalah salah seorang wali Allah seperti tersurat pada judul buku ini. Di dalamnya ada penjelasan tentang ajaran TQN yang dirumuskan Abah Anom.

6. Buku berjudul "TQN Sejarah, Asal Usul dan Perkembangannya" yang merupakan kumpulan tulisan yang dipublikasikan sebagai kenang-kenangan ulang tahun Suryalaya ke 85 (1905-1990).

\section{Mursyid Waliyullah; TQN Retak}

Abah Anom, dalam keyakinan para ikhwan TQN, bukan hanya seorang mursyid, pembimbing ruhani atau guru tarekat, tetapi seorang wali Allah. Manusia yang dekat, bersahabat dan menjadi kekasih Allah. Dr Asep Salahudin, dosen UIN Sunan Gunung Jati Bandung dan IAILM Suryalaya menulis buku yang berjudul: Abah Anom Wali Fenomenal Abad 21 dan Ajarannya.42 Di dalam buku ini, Kang Asep menulis, "Syaikh Mohammad Nazim Adil al-Haqqani mengatakan, Pangeresa Abah Anom adalah wali agung dari Timur Jauh”. Menurutnya: "Allah adalah cahaya langit dan bumi. Cahaya Allah disampaikan kepada Nabi Muhammad saw, lalu beliau meneruskannya kepada para sahabatnya, dan para sahabatnya meneruskan lagi kepada generasi-generasi saleh berikutnya. Dari mereka cahaya itu terus mengalir kepada orang-orang yang siap dan mau menerimanya. Maka, anda sekalian para hadirin, ambilah Nur Ilahi itu dari beliau saat ini. Mumpung beliau masih hadir di tengah kita, sulutkan Nur Ilahi dari kalbu beliau kepada kalbu Anda masing-masing”. 43

Sejalan dengan keyakinan Syaikh Nazim, para ikhwan TQN meyakini bahwa Abah Anom adalah wali Allah. Mereka pun meyakini bahwa beliau memiliki karamah yang melimpah. Pada 
malam sebelas, sejak waktu sahur hingga subuh Masjid di komplek Pesantren Suryalaya penuh sesak oleh para ikhwan yang shalat malam dan berdzikir dengan suara bergema hingga adzan subuh berkumandang. Sesusai shalat subuh berjamaah, para ikhwan bergerak menuju Madrasah, tempat kediaman Abah Anom. Mereka mengikuti antrian panjang untuk bisa bersalaman dan mencium tangan Abah Anom. Antrian ini diikuti ribuan orang, tua, muda, laki-laki, perempuan, bahkan anak-anak hingga menjelang acara manakiban dimulai pada pukul o8.oo wib. Para ikhwan umumnya membawa botol air minum mineral untuk mendapatkan doa dan berkah dari pemimpin spiritual mereka. Air yang sudah diberkahi ini biasanya digunakan untuk menyembuhkan penyakit, menolak malapetaka dan mendatangkan kemudahan dalam hidup dan kehidupan. 44

Kini, ketika mursyid TQN Suryalaya itu diproklamirkan berada di tangan Abah Aos, maka secara otomatis Abah Aos pun diyakini telah menjadi wali Allah dan diperlakukan oleh para ikhwan TQN sebagaimana mereka memperlakukan Abah Anom. Dalam Majalah Nuqthoh No 7 Tahun XI Rajab 1435 H/Mei 2014 di bawah judul "Abah Aos Q.S. (qaddasallahu sirrah) Sang Pelestari Cahaya" dinyatakan secara terbuka tentang kemursyidan Abah Gaos. "Syaikh Muhammad Abdul Gaos Saefulloh Maslul Al-Qodiri An-Naqsyabandi Al-Kamil Wali Mursyid TQN Suryalaya Silsilah ke-38".45 Pernyataan ini bukan hanya menegaskan bahawa Ajengan Gaos sudah dinobatkan sebagai Mursyid TQN ke-38 menggantikan Abah Anom, tetapi juga menyatakan bahwa Ajengan Gaos adalah seorang waliyullah, al-Kamil, yang sempurna. Abah Gaos pun diyakini sebagai seorang yang memiliki keistimewaan atau karamah. "Berbagai keistimewaan gerak dakwah Abah Aos dalam mengembangkan TQN PP Suryalaya pada zaman kemursyidan Abah Anom tidak dimiliki oleh Wakil Talqin lainnya. Sedemikan sehingga pantaslah jika pada saat ini, Abah Aos Qs menjadi penerus Abah Anom dalam melestarikan cahaya TQN Suryalaya. Keistimewaan Abah Aos Qs dalam melestarikan cahaya TQN Suryalaya tentu saja jika harus ditulis keseluruhan daripada keistimewaan tersebut, maka satu buku pun tidak akan cukup untuk memuatnya. Jangankan satu buku, jika pun seluruh ikhwan TQN Suryalaya bimbingan Abah Aos Qs diberikan tugas untuk menuliskan keistimewaan-keistimewaan beliau versi masing-masing, maka tentu saja tidak akan mencukupi untuk dimuat di salah satu perpustakaan, sekalipun itu satu perpustakaan terbesar di dunia”. 46

Sementara itu, menurut Pak Beben, "siapa pun tidak dibenarkan menyatakan dirinya sebagai mursyid TQN ke 38 menggantikan beliau. Saya tidak bermaksud mendiskriditkan seseorang. Saya hanya ingin menyatakan bahwa tidak dibenarkan seseorang mengaku dirinya sebagai mursyid TQN ke-38, apa lagi menyebar luaskan pengakuannya kepada orang banyak. Saya tidak bermaksud memfitnah, tetapi klarifikasi, penjelasan atau tabayyun itu penting. Saya tidak bermaksud membicarakan seseorang secara personal, saya hanya menyatakan ketika orang ini mengangkat 80 orang lebih Wakil Talqin TQN, maka pengangkatan itu sah, karena untuk membantu orang-orang yang ingin belajar dzikir, tetapi ketika mengaku dirinya sebagai mursyid TQN ke 38 dan menyebar luaskan pengakuannya kepada orang banyak, maka ini sudah merupakan langkah-langkah teknis adu kecepatan agar tidak didahului (menjadi mursyid ke-38) dengan motiv sesuatu yang bersifat 
materi. Saya tidak bermaksud memfitnah, tetapi langkah tersebut sudah bergeser dari keikhlasan. Menyebut dirinya (sebagai mursyid ke-38) sebagai seorang yang al-kamil al-mutakammil (yang sempurna lagi menyempurnakan) merupakan kesombongan, padahal kita ini bodoh di hadapan Allah. Yang al-Kamil, Mahasempurna, hanya Allah. Menisbahkan al-Kamil kepada dirinya sendiri dalam tasawuf membatalkan kewalian atau kemursyidan, sehingga berakibat bathalat walâyatuhu, batal kewaliannya. Mudah-mudahan Allah menyempurnakan kekurangan kita”.47

Perjuangan mantan Wakil Talqin Abah Anom ini tidak berhenti pada deklarasi dirinya sebagai mursyid TQN ke-38, tetapi juga dengan memindahkan pusat kegiatan TQN Suryalaya dari Godebag ke Ciceuri, dari Suryalaya ke Sirnarasa yang terletak di Kecamatan Panjalu Kabupaten Ciamis. Pengalihan pusat kegiatan TQN ini, menurut Majalah Nuqthoh hanya soal tempat, bukan soal substansi. "Satu hal yang harus kita catat bahwa Pesantren Sirnarasa bagaikan jasad, tetapi ruhnya adalah Suryalaya seperti halnya jasad Abah Aos ruhnya adalah Abah Anom. Pergerakan Sirnarasa saat ini hingga masa yang akan datang adalah membawa misi pendiri Pondok Pesantren Suryalaya yakni Abah Sepuh yang diterjemahkan oleh Abah Anom secara isyaroh kepada Abah Aos". 48

Sementara itu, Pak Beben menegaskan: "Jangan bersemboyan meneruskan TQN Suryalaya, tetapi faktanya meninggalkan Suryalaya. Kita jangan mengaku menjadi mursyid TQN. Umat, para muhibbin (pecinta) TQN, boleh saja mengatakan mursyid atau waliyullah, tetapi kita tidak meninggalkan Suryalaya dan tidak merasa menjadi mursyid TQN. Kalau kejadiannya seperti dalam sebuah kerajaan, menyatakan dirinya pengganti raja, lalu mendirikan kerajaan sendiri, meninggalkan yang asal. Itu bagaiamana? Saya tidak sedang memvonis seseorang. Sekali lagi, saya tidak memvonis seseorang. Maksudnya, saya takut, karena sedang belajar dzikir, mendekatkan diri kepada Allah dengan kalimat la ilaha illa Allah, saya tidak mau melakukan ghibah, sedangkan tabayyun itu dibolehkan dalam Al-Qur`an. Kita harus melakukan tabayyun, karena Al-Qur`an memerintahkannya. 49

Konflik ini harus dikembalikan kepada hakikat tarekat sebagai sebuah organisasi para pengamal tasawuf amali di bawah kepemimpinan mursyid yang berhasil membentuk sub kultur yang berbeda dari kultur masyarakat pada umumnya. Dalam tarekat, mursyid berada pada puncak piramida. Ia menempati posisi sentral dalam mengarahkan amaliah para pengikut tarekat, bahkan mengontrol totalitas kehidupan mereka; namun, sangat disayangkan Mursyid TQN Suryalaya yang memiliki gaya kepemimpinan kharismatik tidak menggunakan wewenang yang dimilikinya untuk menyiapkan suksesi kepemimpinan yang mulus atau mengeluarkan perintah atau maklumat tentang mursyid pengganti yang tak seorang pun di antara murid-murid tarekat berani mempertanyakan atau menolaknya.

Kini, semuanya sudah berlalu. TQN Suryalaya sudah terbelah, namun solusi kearifan masih terbuka. Mengapa tidak ada syura yang adil dan bermartabat yang merangkul semua komponen TQN sesuai anjuran Tanbih yang setiap manakiban dibacakan dan disimak oleh para ikhwan? Seharusnya spirit untuk rekonsiliasi itu ada dengan keyakinan bahwa pada diri para pengamal 
tarekat itu ada kesucian hati yang berkorelasi dengan kearifan untuk menyatukan kembali TQN yang retak.

\section{Tradisi Manakiban: Penghormatan kepada Syaikh 'Abdul Qadir al-Jilani yang Berlebihan}

Dalam tradisi Pesantren Suryalaya, manakiban diselenggaralan sebulan sekali, setiap tanggal sebelas bulan qamariah, karena tanggal ini diyakini merupakan tanggal wafatnya Syaikh 'Abd alQâdir al-Jaylânî. Acara manakiban berlangsung sejak pagi hingga menjelang lohor. Susunan acara inti manakiban terdiri atas dua bagian, khidmat amaliah dan khidmat ilmiah. Khidmat amaliah berupa ritual yang terdiri atas empat kegiatan: Pembacaan Al-Qur`an, tawasul, pembacaan tanbih dari Abah Sepuh dan pembacaan manqabah; sedangkan khidmat ilmiah terdiri atas dua kegiatan utama, yaitu: Kajian Kitab Miftâh al-Shudûr dan ceramah tentang tasawuf dan tarekat; kemudian doa penutup oleh Mursyid atau Wakil Mursyid (Wakil Talqin) yang ditunjuk. 50

Manakiban tidak hanya diselenggarakan di Suryalaya, tetapi juga di setiap daerah yang jumlah ikhwan TQN-nya memungkinkan untuk menyelenggarakan manakiban. Kegiatan ini dikelola oleh Pengurus Yayasan Serba Bakti Pesantren Suryalaya Bidang Ilmu dan Da’wah. Mereka mengundang para ikhwan TQN, menyususn jadwal dan menunjuk para petugas, termasuk menunjuk mubaligh TQN untuk mengisi khidmat ilmiah. Manakiban pada umumnya dilaksanakan di rumah salah seorang ikhwan TQN yang kapasitasnya luas, bisa menampung puluhan ikhwan, menyediakan konsumsi dan menanggung transport para petugas, terutama para mubaligh. ${ }^{51}$

Manqabah yang dipilih dan dibaca dalam setiap manakiban berbeda-beda untuk tiap-tiap bulan dalam satu tahun. Berikut ini contoh manqabah yang dibaca pada bulan Muharam, yaitu manqabah ke-40 yang menyebutkan bahwa Syaikh 'Abdul Qadir al-Jilani diberi buku untuk mencatat murid-muridnya sampai hari kiamat yang paparan lengkapnya sebagai berikut:

'Diriwayatkan di dalam kitab "Bahjatul Asrar", Syaikh 'Abdul Qadir pernah berkata : “Aku diberi sebuah buku yang luasnya sejauh mata memandang untuk menuliskan nama-nama muridku sampai hari kiamat. Semua murid itu telah Allah berikan Kepadaku dan telah menjadi milikku. Aku pernah bertanya Kepada malakul Malik, "Apakah ada dalam neraka, muridku dan sahabat-ku ?” Malakul Malik menjawab: “tidak ada.”

Syaikh berkata : "Aku bersumpah, demi kemuliaan Tuhanku. Tanganku atas muridmuridku seperti langit menutup bumi. Andaikan murid-muridku itu buruk, maka akulah yang baik. Dan aku bersumpah, demi Ke-Agungan dan Kemuliaan Tuhanku, dua telapak kakiku tidak akan bergeser di hadapan Tuhan kecuali sudah mendapat keputusan bahwa aku bersama-sama muridku masuk surga"

Lebih lanjut beliau bersabda : "Tanganku tidak akan lepas dari kepala murid-muridku, walaupun aku sedang ada di Timur dan muridku ada di Barat, lalu muridku itu tersingkap auratnya, maka tanganku akan segera menutupinya. Demi Keagungan dan Kemuliaan Tuhanku, pada hari qiamat aku akan berdiri tegak di hadapan gerbang neraka, sekali lagi aku 
tidak akan bergeser sebelum muridku masuk surga karena Allah Yang Maha Kuasa telah menjanjikan kepadaku bahwa murid-muridku tidak akan dimasukan ke dalam neraka. Barang siapa berguru serta mahabbah kepadaku, pasti aku menghadap kepadanya, bahwa mereka dan Malaikat Munkar Nakir telah berjanji kepadaku, bahwa mereka tidak akan menakut-nakuti murid-muridku." $5^{2}$

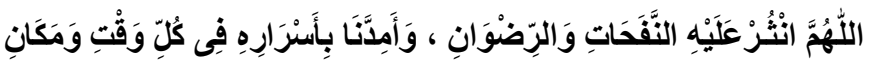

Dalam disertasi Dr Ajid Thohir, staf pengajar UIN Sunan Gunung Jati Bandung, berjudul "Historisitas dan Signifikasi Kitab Manaqib Syaikh 'Abdul Qadir al-Jilani Dalam Historiografi Islam" disebutkan bahwa "Kitab Manaqib Syaikh "Abdul Qadir al-Jilani menempati posisi akademis yang cukup problematis. Bukan hanya obyek dan temanya yang dianggap kaum positivis terlalu masuk pada wilayah-wilayah meta-historis, metodologi dan epistemologinya, paradigma penulisan dan sumber-sumber yang digunakannya, gaya dan retorika penulisannya yang cenderung lebih bersifat penyanjungan, dan masih banyak lagi hal lain yang mengundang banyak perdebatan ilmiah di dalamnya".53

Menyimak pesan yang tersurat dan tersirat pada manqabah ke- 40 di atas, pikiran kita dibawa ke alam mitologi, yang menurut Ajid Thohir, masuk pada wilayah-wilayah meta-historis, di luar alur sejarah. Oleh sebab itu, di dalam manqabah itu ada beberapa problematika.

Problem pertama, manqabah atau kisah yang bermuatan karamah Syaikh 'Abdul Qadir alJilani itu tidak bersumber langsung dari beliau, tetapi ditulis oleh orang yang tidak sezaman dengan Syaikh 'Abdul Qadir al-Jilani. Kitab Bahjat al-Asrar yang menjadi sumber manqabah ke 40 di atas ditulis oleh Syaikh Nuruddin Abil Hasan Ali bin Yusuf bin Jarir al-Lakhmi al-Syathnufi yang lahir pada akhir bulan Syawal tahun 647 H/1249 M,54 sedangkan Syekh 'Abdul Qadir alJilani lahir pada tahun $470 \mathrm{H}$. Jarak antara masa hidup SAQJ dengan penulis manqabah cukup jauh sehingga ada problematika pada sanad dan matan, kesinambungan periwayatan dan contents, isi atau substansi manqabah. Hal ini, dengan meminjam istilah 'ulûm al-hadîts, membutuhkan kritik sanad dan kritik matan. Sementara itu, "dalam historiografi sufi, metodologi penulisan sejarah yang dilakukan kaum sufi, penulisan sejarah itu berkaitan dengan rekaman sosial atau sikap masyarakat yang mengabadikan ingatan masa lalu, baik yang ditunjukkan oleh cerita rakyat, termasuk mitologi yang selalu hadir di tengah-tengah mayarakat”. 55 Jadi, sangat mungkin kisah di dalam manqabah tersebut bersumber dari cerita rakyat yang bersifat mitos atau mitologi, bukan peristiwa sejarah yang dilakukan oleh Syaikh 'Abdul Qadir al-Jilani.

Motvasi Syaikh Nuruddin Abil Hasan Ali dalam menulis Kitab Bahjat al-Asrar, menurut Drewes dan Poerbatjaraka seperti ditulis Ajid Thohir, adalah (menjadikan kitab ini ) sebagai pembuktian keberadaan karamah wali serta pelajaran (al-ibrah) bagi mereka yang membutuhkannya”. ${ }^{6}$ Jadi motivasi penulisan Kitab Manaqib Syaikh 'Abdul Qadir al-Jilani untuk membuktikan adanya karamah wali, yang bersifat khawâriq al-âdah, bertentangan dengan 
hukum alam, bukan untuk mengkaji sejarah hidup atau biografi Syaikh 'Abdul Qadir al-Jilani; dan untuk menjadi ‘ibrah bagi mereka yang membutuhkannya.

Problema kedua, berkenaan dengan isi atau substansi manqabah ke-40 sehingga manqabah ke-40 itu harus ditelaah ulang karena keseluruhan isinya tidak sejalan dengan ajaran dasar AlQur`an dan Sunnah Nabi saw sebagai berikut:

Dalam manqabah ke-40 di atas, baik secara tersurat maupun tersirat sangat kuat adanya suatu keyakinan bahwa Syaikh 'Abdul Qadir al-Jilani memiliki buku induk yang mencatat muridmurid beliau hingga hari kiamat. Keyakinan seperti ini tidak diajarkan oleh Rasulullah saw dan tidak ada di dalam Al-Qur`an. Apa lagi ujaran yang menyatakan: "Semua murid itu telah Allah berikan Kepadaku dan telah menjadi milikku”. Maksudnya, pada hari kiamat keselamatan muridmurid beliau, para pengamal Tarekat Qadiriyah, tidak berada di tangan Allah, karena telah terjadi pelimpahan wewenang dari Allah kepada Syaikh 'Abdul Qadir. Keyakinan serupa ini bertentangan dengan beberapa ayat Al-Qur`an yang berikut:

$$
\text { وَنَرِثُثُهُ مَا يَقُولُ وَيَانْيَنَا فَرْدًا }
$$

dan Kami akan mewarisi apa yang dia katakan itu, dan dia akan datang kepada Kami seorang diri. (Q.S. Maryam/19: 80).

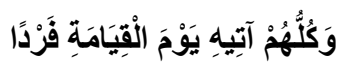

Dan setiap orang dari mereka akan datang kepada Allah sendiri-sendiri pada hari Kiamat (Q.S. Maryam/19: 95).

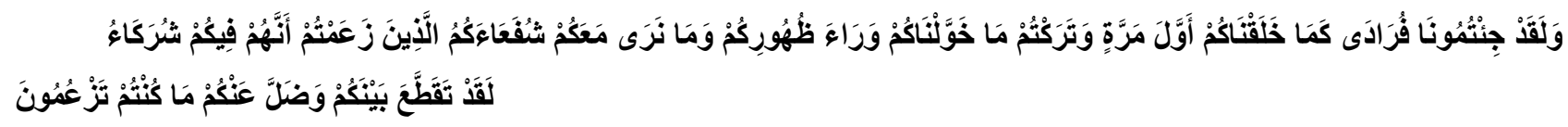

Dan kamu benar-benar datang sendiri-sendiri kepada Kami sebagaimana Kami ciptakan kamu pada mulanya, dan apa yang telah Kami karuniakan kepadamu, ku tinggalkan di belakangmu (di dunia). Kami tidak melihat pemberi syafaat (pertolongan) besertamu yang kamu anggap bahwa mereka itu sekutu-sekutu (bagi Allah). Sungguh, telah terputuslah (semua pertalian) antara kamu dan telah lenyap dari kamu apa yang dahulu kamu sangka (sebagai sekutu Allah). (Q.S. alAn'am/6: 94)

\section{Berbagai Ritual yang Tidak Bersumber dari Ajaran Islam}

Amaliah pelatihan ruhani (al-riyâdhah al-rûhiyyah) di dalam TQN Suryalaya, seperti disampaikan Rahmat Effendi, ikhwan dan menantu Abah Anom, meliputi empat hal, yaitu amaliah bulanan (manakiban), mingguan (khataman), dan harian (dzikir dan shalat), serta ritual insidental (riyadhah). Di antara empat ritual itu ada yang dilakukan secara kolektif (manakiban), kolektif dan perorangan (khataman, dzikir dan shalat) dan juga perorangan (riyadhah). Ada beberapa riyadhah yang diajarkan mursyid TQN yang diduga tidak bersumber dari ajaran Islam, di antaranya: 
a. Mandi malam selama empat puluh hari;

b. Melek (tidak tidur) empat puluh hari;

c. Beubeutian (hanya makan ubi-ubian) selama empat puluh hari;

d. Niis (tidak makan makanan bergaram) selama empat puluh hari;

e. Kamanusaan (kemanusiaan) dengan cara tidak makan daging selama emapat puluh hari;

f.Kamalaikatan (kemalaikatan) yaitu mandi empat puluh kali setiap malam hari dan badan harus kering dengan sendirinya (tidak memakai handuk);

g. Membaca wirid Hizbul Yaman selama empat puluh hari.

Pelatihan ruhani ini, menurut Rahmat Effendi, sebagai bentuk pelatihan jiwa untuk mengembangkan kepekaan rasa dan meraih rasa yang kosong. 57

Dari ketujuh ritual di atas mungkin hanya satu ritual yang diperkirakan masih berada dalam koridor wirid dzikir, yaitu wirid Hizbul Yaman selama empat puluh hari dengan catatan bahwa content wirid ini tidak ada yang menyimpang dari wirid yang diajarkan oleh Rasulullah saw. Sementara itu keenam ritual lainnya merupakan ritual yang lazim dalam tradisi negelmu batin yang merupakan bagian dari latihan menekung ing ngasepi (bermeditasi dalam sepi), olah rasa, eling (selalu sadar), meper nepsu (menahan hawa nafsu), tirakat (laku ritual) dan mawas diri guna melahirkan jumbuh (keharmonisan) anara jagad kasar dengan jagad alus dalam dirinya; yang pada gilirannya akan melahirkan tata eksistensi yang harmonis dalam kosmos. ${ }^{8}$

Melek (tidak tidur) empat puluh hari, beubeutian (hanya makan ubi-ubian) selama empat puluh hari, niis (tidak makan makanan bergaram) selama empat puluh hari, kamanusaan (kemanusiaan) dengan cara tidak makan daging selama emapat puluh hari; kamalaikatan (kemalaikatan) yaitu mandi empat puluh kali setiap malam hari dan badan harus kering dengan sendirinya (tidak memakai handuk); tidak pernah dilakukan oleh Rasullah saw sepanjang hidup beliau. Nabi Muhammad saw tidak pernah melakukan; tidak pernah mencontohkan dan tidak pernah memerintahkannya kepada para sahabat; sebaliknya beliau melarang kaum Muslimin melakukan semua ritual tersebut. Allah menegaskan di dalam ayat Al-Qur`an yang berikut:

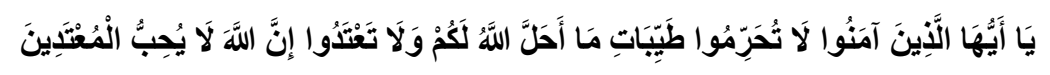

Wahai orang-orang yang beriman! Janganlah kamu mengharamkan apa yang baik yang telah dihalalkan Allah kepadamu, dan janganlah kamu melampaui batas. Sesungguhnya Allah tidak menyukai orang-orang yang melampaui batas. (Q. S. Al-Ma `idah/5: 87).

Dalam menafsirkan ayat di atas, Syaikh Musthafa al-Maraghi menyatakan:

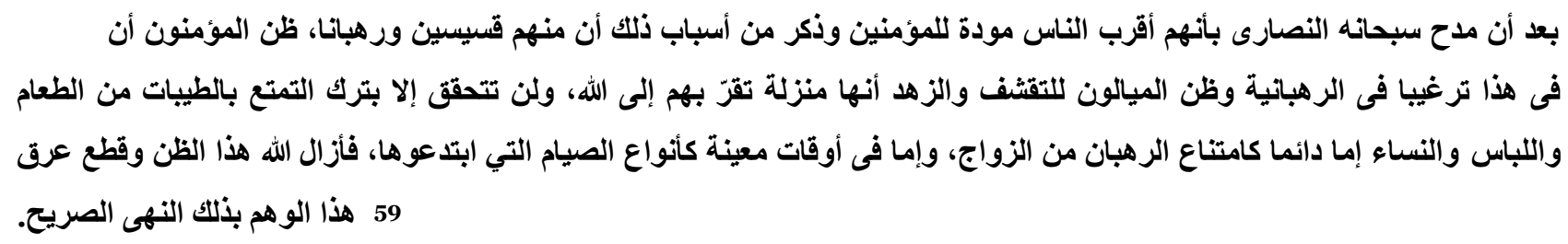


Setelah pada sayat sebelumnya (pada ayat 82) Allah swt memberikan pujian kepada kaum Nasrani dengan menyatakan bahwa mereka adalah manusia yang paling dekat hubungan kasih sayangnya terhadap orang-orang mu `minin, karena di antara mereka ada para pendeta dan para rahib; di antara orang-orang beriman ada yang mengira bahwa hal ini merupakan dorongan (AlQur`an) untuk menjalani hidup kependetaan dan cenderung kepada kehidupan asketis (al-zuhd) sebagai maqam yang mendekatkan mereka kepada Allah; yang tidak akan pernah terwujud kecuali dengan meninggalkan berbagai kenikmatan yang halal dan berkualitas, makanan, pakaian dan menikahi perempuan; baik yang bersifat permanen seperti larangan para pendeta untuk menikah maupun yang bersifat sementara pada waktu-waktu tertentu dengan melakukan puasa yang mereka ciptakan. Lalu Allah menghapuskan dugaan-dugaan ini dengan memotong urat nadi keyakinan palsu dengan larangan yang jelas pada ayat di atas.

Selain ayat Al-Qur`an di atas, perhatikanlah pula sabda Rasulullah saw yang berikut:

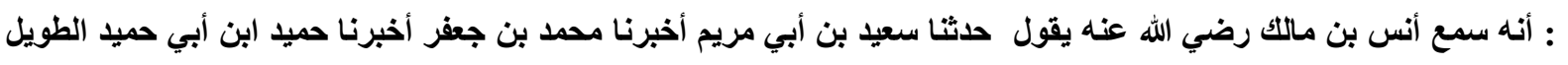

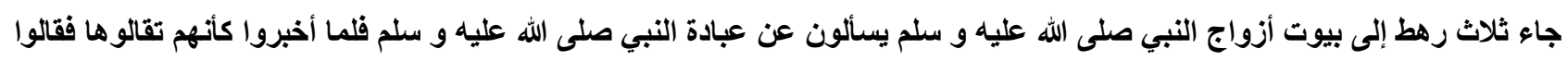

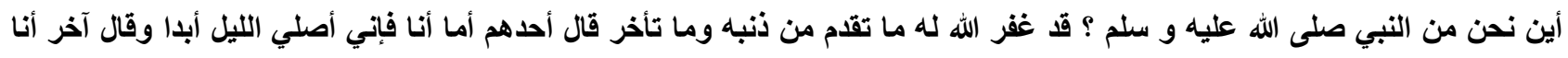

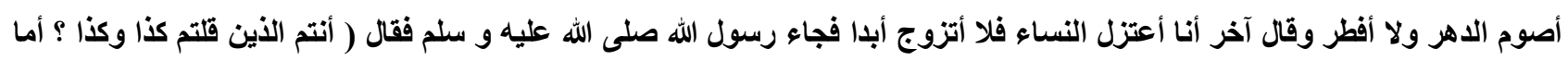
60 و 60

Sa’id bin Abi Maryam meceriterakan kepada kami, telah mengabarkan kepada kami Muhammad bin Ja'far; telah mengabarkan kepada Hamid bin Abi Hamid bahwa ia mendengar Anas bin Malik r.a. berkata: Tiga orang datang ke rumah istri-istri Rasulullah saw menanyakan tentang ibadah Rasulullah saw, ketika diberitahukan seakan-akan mereka mendengar gurauan. Mereka berkata, bagaimana ibadah kami dibandingkan dengan ibadah Rasulullah saw, sungguh Allah telah memberikan ampunan kepada beliau atas dosa beliau yang lalu dan yang akan datang? Kemudian salah seorang di antara mereka berkata: "Aku selamanya shalat sepanjang malam". Yang lain berkata: "Saya puasa sepanjang tahun dan tidak pernah berbuka". Yang lain berkata: "Saya menjauhi perempuan, saya tidak menikah selamanya". Lalu datang Rasulullah saw kemudian bersabda: "Kalian yang mengatakan demikian dan demikian? Demi Allah, sungguh aku adalah orang yang paling takut di antara kalian kepada Allah dan paling bertakwa kepada-Nya, tetapi aku berpuasa dan aku pun berbuka; aku shalat malam dan aku pun tidur; dan aku pun menikahi perempuan-perempuam; barangsiapa yang membenci sunahku, maka ia bukan umatku”.

\section{Simpulan}

Dengan demikian, berbagai ritual dalam TQN Suryalaya sebagaimana disebutkan di atas . Hal itu merupakan kreasi mursyid yang mengira bahwa ritual-ritual itu merupakan cara untuk mendekatkan diri kepada Allah, padahal sejatinya merupakan perbuatan yang tidak ada tuntunannya dari Allah dan Rasul-Nya. Jika pada uraian di atas, al-Maraghi menjelaskan bahwa sebagian orang-orang beriman meninggalkan berbagai kenikmatan makanan, pakaian dan 
menikahi perempuan itu karena mengikuti para rahib, tradisi TQN boleh jadi mengikuti tradisi ngelmu batin yang merupakan warisan agama-agama sebelum Islam atau agama karuhun (nenek moyang). Wa Allahu a'lam bi al-shawwab

\section{Catatan Kaki}

${ }^{1}$ Jamal al-Din Abi al-Fadhal Muhammad bin Makram Ibn Manzhur al-Anshari, Lisan al-'Arab, cet. Ke-1, Juz ke-10, (Beirut: Dar al-Kutub al-'Ilmiyah, 2003/1424), h. 258, 265 dan 266;

${ }^{2}$ L. Ma'luf, al-Munjid fi al-Lughah, cet. Ke-39, (Beirut: Dar al-Masyriq, 2002), h. 165.

3 Muhammad "Aqil bin "Ali al-Mahdali, "Dirâsat fi al-Thuruq al-Shûfiyyah", dalam Futuhal Arifin, (penterj.), Mengenal Tarekat Sufi, cet. Ke-1, (Jakarta: Penerbit Azan, 2002), h. 3.

4 Hans Wehr, A Dictionary of Modern Written Arabic, (ed.) J Milton Cowan, cet. Ke-3, (Beirut: Maktabah Lubnan, 1980), h. 559 .

5 Nurcholish Madjid, Selayang Pandang tentang Tarekat di Indonesia dan Masa Depannya, Seri Klub Kajian Agama ke-86/Tahun VIII/1994, h. 3.

${ }^{6}$ Sayyid Abu Bakar al-Makki dalam Kitab Kifâyat al-Atqiyâ ${ }^{`}$ wa Minhâj al-Ashfiyâ ${ }^{\prime}$ menulis sebuah sya'ir yang berikut: فشريعة كسفينة وطريقة كالبحر ثم حقيقة در غلا (Syari'at itu perahu, tarekat itu samudera, hakikat itu mutiara yang sangat berharga), h. 9 .

7 Ahmad Tafsir, Tarekat dan Hubungannya Dengan Tasawuf, dalam (ed), Harun Nasution, cet. Ke-1, "Thoriqot Qodiriyyah Naqsyabandiyyah: Sejarah, Asal-usul dan Perkembangannya", (Tasikmalaya: Institut Agama Islam Latifah Mubarokiyyah, 1990), 27.

8 Asep Usman Ismail, Tasawuf, dalam H.M. Quraish Shihab dan H. Ahmad Sukardja, (ed) "Ensiklopedi Tematik Dunia Islam", jilid 3, cet, ke-1, (Jakarta: PT Ichtiar Baru van Hoeve, 2001), 317.

9 Perkataan songo pada walisongo, menurut K.H.R. Moch Adnan, merupakan perubahan pengucapan tsana dalam bahasa Arab yang berarti mulia atau terpuji sehingga pengucapan yang benar adalah walisana yang berarti wali yang mulia, K.H. Saifuddin Zuhri, Sejarah Kebangkitan Islam dan Perkembangannya di Indonesia, cet. Ke-2, (Bandung: PT Al-Ma'arif, 1980), h. 260.

10 Lihat: Ahmad Purwadaksi, Tarekat dan Masa Depannya, dalam Muhammad Wahyuni Nafis, (ed), “Rekonstruksi dan Renungan Religius Islam” cet. Ke-1, (Jakarta: Penerbit Paramadina, 1996), 305.

${ }_{11}$ Tujimah, Syaikh Yusuf Makasar: Riwayat Hidup, Karya dan Ajarannya, cet. Ke-1, (Jakarta: Dep. P dan K, 1987), h. 5 .

${ }_{12}$ Naskah Palembang, "Shadiq ibn Umar Khan: Qathf Izhâr al-Mawâhib al-Rahbâniyyah min Afnân Riyâdl al-Qashîdah li al-‘Ârif bi al-Lâh Sayyid al-Syaikh Muhammad alamman”, (t.t.), h. 136

${ }^{13}$ Ahmad Tafsir, Tarekat dan Hubungannya dengan Tasawuf, h. 33.

${ }^{14}$ H.S. Nyberg, Kleimer Schriften Des Ibn al-'Arabî: Kitâb Insyâ 'al-Dawâ 'in, Kâtab 'Uqlat al-Mustawfid wa Kitâb Tadbîrat al-Ilâhiyah fỉ Islâh al-Mamlahat al-Insâniyah, (Leiden: E.J. Brill, 1919), h. 226-227 sebagaimana dikutip Ahmad Purwadaksi, Tarekat dan Masa Depannya, h. 203

15 Tudjimah, Syaikh Yusuf Makasar, h. 70.

${ }^{16}$ Naskah Palembang, h. 136

${ }_{17}$ Ahmad Purwadaksi, Tarekat dan Masa Depannya, Seri Klub Kajian Agama ke-86/Tahun VIII, Jakarta 27 Mei 1994, h. 4.

${ }_{18}$ Ahmad Purwadaksi, "Ratib Saman dan Hikayat Syaikh Muhammad Samman: Suntingan Naskah dan Kajian Isi Teks", Disertasi, (Jakarta: Universitas Idonesia, 1992), h. 425.

19 Hawash Abdullah, Perkembangan Ilmu Tasawuf dan Tokoh-tokohnya di Nusantara, (Surabaya: AlIkhlas, 1980), h. 177.

${ }^{20}$ Syaikh Ahmad Khatib Sambas, "Kitab Fathul Arifin", dalam Hawash Abdullah, Perkembangan Ilmu Tasawuf dan Tokoh-tokohnya di Nusantara, h. 182-193.

${ }_{21}$ Pabali, Latar Belakang Sosial Politik Tarekat Qadiriyah wa Naqsyabandiyah Ahmad Khatib Sambas (1802-1878), disertasi Sekolah Pascasarjana UIN Syarif Hidayatullah Jakarta, 2008), h. 181.

${ }^{22}$ Syaikh "Abd al-Qadir al-Jaylani, "Futûh al-Ghayb", dalam (penterjemah), Abdullah Zaky Al-Kaaf, Ajaran-ajaran Kegaiban, (Bandung: Pustaka Setia, 2004), 11 dan 20.

23 Pabali, Latar Belakang Sosial Politik Tarekat Qadiriyah wa Naqsyabandiyah Ahmad Khatib Sambas (1802-1878), 181.

24 Asep Usman Ismail, Abd al-Qadir al-Jaylani, dalam Tim Penulis UIN Syarif Hidayatullah Jakarta, "Ensiklopedi Tasawuf" Jilid I, cet. Ke-1, (Bandung: Penerbit Angkasa, 2008), h. 24.

${ }^{25}$ Syaikh Abd al-Qadir al-Jaylani, Al-Fath al-Rabbani, h. 108.

${ }^{26}$ Syaikh 'Abd al-Wahhab al-Sya'rani, Thabaqât al-Kubrâ, ( Al-Qahirah: Maktabah Ali al-Shabih, t.t.) h. 109. 
27 Zamakhsyari Dhofier, Tradisi Pesantren: Studi tentang Pandangan Hidup Kyai, cet. Ke-1, (Jakarta: LP3ES, 1984), h. 141.

28 R.H. Unang Sunardjo, "Pesantren Suryalaya Dalam Perjalanan Sejarahnya", dalam H. Achmad Sanusi, Abah Sepuh dan Pembentukan TQN Pondok Pesantren Suryalaya: Kenang-ketangan Ulang Tahun Pesantren Suryalaya Ke-85 (1905-1990), dalam (ed), Harun Nasution, “Thoriqot Qodiriyyah Naqsyabandiyyah Sejarah, Asal Usul dan Perkembangannya”, cet. Ke-1, (Tasikmalaya: IAILM, 1990$)$, 97.

29 Sri Mulyati, Abah Anom, dalam Azyumardi Azra, pemred, "Ensiklopedi Tasawuf", jilid I, cet. Ke-1, (Bandung: Penerbit Angkasa, 2008), h. 2.

3o KH. Ahmad Shohibul Wafa Tadjul Arifin, Mifâth al-Shudûr, dalam (ed) Harun Nasution, "Thoriqot Qodiriyyah Naqsyabandiyyah: Sejarah, Asal Usul dan Perkembangannya”, cet. Ke-1, (Tasikmalaya: IAILM, 1990), h. 304.

${ }^{31}$ Lihat: Madrasah TQN PP Suryalaya, Kitab 'Uqudul Juman, cet. Ke-1, (Tangerang Selatan, Pesantren Internasional Jagat 'Arasy, 2013), h. xiii-xv.

32 Asep Usman Ismail, "Manakiban” dalam Tim Penulis UIN Syarif Hidayatullah Jakarta, Ensiklopedi

Tasawuf, Jilid II, cet. Ke-1, (Bandung: Penerbit Angkasa, 2008), h. 763-764.

33 Wawancara pribdi dengan K.H. Beben Pamijahan pada Jum'at 3 Syawal 1437 H/8 Juli 2016

34 Wawancara pribdi dengan K.H. Beben Pamijahan pada Jum'at 3 Syawal 1437 H/8 Juli 2016

35 Wawancara pribdi dengan K.H. Beben Pamijahan pada Jum'at 3 Syawal 1437 H/8 Juli 2016

${ }^{6} 6$ Nuqthoh No 7 Tahun XI Rajab 1435 H/Mei 2014 H, h. 7

37 Nuqthoh No 7 Tahun XI Rajab 1435 H/Mei 2014 H, h. 7-8.

38 Madrasah TQN PP Suryalaya Pesantren Internasional Jagat Arasy, "Kitab Uqudul Juman Thoriqoh Qodiriyyah Naqsyabandiyyah Pondok Pesantren Suryalaya”, (Tangerang Selatan, Jagat 'Arasy, 2013).

39 Pondok Pesantren Suryalaya, Amaliyah Mursyid: Amalan Thoriqot Qoodiriyyah Naqsyabandiyyah

Pondok Pesantren Suryalaya, Cet. Ke-1, (Bandung: Wahana Karya Grafika, 2013).

40 KHM Abdul Gaos Saefulloh Maslul, Saefulloh Maslul Menjawab 165 Masalah, cet. Ke-1, Bandung: Wahana Karya Grafika, 2006).

${ }^{41}$ Asep Salahudin, Dr., Abah Anom Wali Fenomenal Abad 21 \& Ajarannya, cet. Ke-1, (Jakarta: Noura Books, 2013).

42 Asep Salahudin, Abah Anom Wali Fenomenal Abad 21 \& Ajarannya, cet. ke-1, (Jakarta: Noua Books, 2013)

43 Asep Salahudin, Abah Anom Wali Fenomenal Abad 21 \& Ajarannya, h. 62

44 Asep Usman Ismail, Manakiban, dalam Tim Penulis UIN Syarif Hidayatullah Jakarta, "Ensiklopedi

Tasawuf", cet. ke-1, jilid II, (Bandung: Penerbit Angkasa, 2008), h. 265.

45 Nuqthoh Bacaan Pembuka Hati, Edisi No 7 Tahun XI Rajab 1435 H/Mei 2014 M., h. 7-9.

46 Nuqthoh Bacaan Pembuka Hati, Edisi No 7 Tahun XI Rajab 1435 H/Mei 2014 M., h. 9-10.

47 Wawancara pribadi peneliti dengan KH Beben Pamijahan pada Jum'at, 8 Juli 2016 M/3 Syawal 1437 H.

48 Asep Usman Ismail, Apakah Wali Itu Ada: Menguak Makna Kewalian Dalam Tasawuf Pandangan alHakim al-Tirmididzi dan Ibn Taymiyah h 86-79.

49 Wawancara pribadi peneliti dengan KH Beben Pamijahan pada Jum'at, 8 Juli 2016 M/3 Syawal 1437 H.

50 Asep Usman Ismail, manakiban, dalam Tim Penulis UIN Syarif Hidayatllah Jakarta, "Ensiklopedi

Tasawuf", cet. ke-1, Jilid II, (Bandung: Penerbit Angkasa, 2008), h. 263.

${ }^{1}$ Asep Usman Ismail, Manakiban, dalam Tim Penulis UIN Syarif Hidayatullah Jakarta, "Ensiklopedi

Tasawuf”, cet. ke-1, jilid II, (Bandung: Penerbit Angkasa, 2008), h. 265.

$5^{2}$ Madrasah TQN PP Suryalaya, Kitab 'Uqûd al-Juman Thoriqoh Qadiriyyah wa al-Naqsyabandiyyah h 118

53 Ajid Thohir, Historisitas dan Signifikasi Kitab Manaqib Syekh Abdul Qadir al-Jilani Dalam Historiografi Islam, cet. ke-1, (Jakarta: Kementerian Agama RI, 2011), h. xi.

54 Ajid Thohir, Historisitas dan Signifikasi Kitab Manaqib Syekh Abdul Qadir al-Jilani Dalam Historiografi Islam, h. 258.

55 Ajid Thohir, Historisitas dan Signifikasi Kitab Manaqib Syekh Abdul Qadir al-Jilani Dalam Historiografi Islam, h. 70.

56 Ajid Thohir, Historisitas dan Signifikasi Kitab Manaqib Syekh Abdul Qadir al-Jilani Dalam Historiografi Islam, h. 259-260.

57 Asep Salahudin, Abah Anom Wali Fenomenal Abad 21 \& Ajarannya, cet. ke-1, (Jakarta: Noura Books, 2013), h 126.

${ }^{8}$ H. Sa'di, Nilai Kesehatan Mental Dalam Kebatinan Kaweuh Jiwa Suryomentaram, cet. ke-1, (ed) Nurman Kholis, (Jakarta: Kementerian Agama RI, 2010), h. 2

59 Ahmad Musthafa al-Maraghi, Tafsir al-Maraghi, cet. ke-1, jilid III, (Beirut: Dar al-Fikr 2001 M/1421 H), h. 6 .

6o Shahih al-Bukhari, Bâb al-Targhîb bi al-Nikâh, Juz 5 h. 1949. 
Asep Usman Ismail, Guru Besar Tasawuf Fakultas Ilmu Dakwah dan Ilmu Komunikasi UIN Syarif Hidayatullah Jakarta

Artikrl ini bersumber dari makalah yang disampaikan pada Forum Diskusi DosenFakultas Ilmu Dakwah dan Ilmu Komunikasi Rabu, 7 Nopember 2018 